\title{
Patientenbefragung
}

\section{Faktoren, die Akne begünstigen}

Schlechte Ernährungsgewohnheiten, erhöhter Stress und aggressive Hautpflegeroutinen gehören zu den maßgeblichsten Faktoren, die mit Akne in Verbindung gebracht werden.

Akne betrifft schätzungsweise jeden zehnten Menschen weltweit und ist damit die achthäufigste Krankheit der Welt. Eine auf dem 28. EADV-Kongress in Madrid vorgestellte Studie hat die Exposition gegenüber unterschiedlichen Faktoren auf Akne bei mehr als 6700 Teilnehmern in sechs Ländern in Nordamerika, Südamerika und Europa untersucht.

Die Ergebnisse der Studie zeigten, dass deutlich mehr Personen mit Akne (48,2\%) täglich Milchprodukte konsumieren als Personen ohne Akne (38,8\%). Die Differenz war auch bei kohlensäurehaltigen Säften oder Sirups (35,6\% gegenüber $31 \%$ ), Gebäck und Schokolade (37\% gegenüber $27,8 \%$ ) und
Süßwaren $(29,7 \%$ gegenüber 19,1\%) statistisch bedeutend. Überraschenderweise konsumieren $11 \%$ von AkneBetroffenen Milchproteine, gegenüber $7 \%$ ohne Akne, und $11,9 \%$ der AkneBetroffenen konsumieren Anabolika, gegenüber 3,2\% ohne Akne.

$\mathrm{Zu}$ den Ergebnissen sagte Forschungsleiterin Prof. Dr. Brigitte Dréno, die die Untersuchung im Auftrag von Vichy Laboratories durchführte: „Akne ist einer der häufigsten Gründe, warum Menschen mit Hautproblemen einen Dermatologen aufsuchen. Die Schwere und die Reaktion auf die Behandlung könnten durch interne und externe Faktoren beeinflusst werden, die wir Exposomen nennen. Mit dieser Studie können nun erstmals die wichtigsten Exposomen-Faktoren für Akne durch eine Patientenbefragung in Erfahrung gebracht werden, bevor eine Behandlung verschrieben wird."

Exposition gegenüber Umweltgiften oder Stress wurden auch häufiger bei Teilnehmern mit Akne beobachtet als bei Kontrollteilnehmern. Die Untersuchung ergab auch, dass aggressive Hautpflegepraktiken häufiger bei Akne-Betroffenen anzutreffen sind.

hautnah $2019 \cdot 18: 117$

https://doi.org/10.1007/s12326-01900355-9

(c) Springer-Verlag GmbH Austria, ein Teil von Springer Nature 2019
Quelle: Presseaussendung apa/ots

Hier steht eine Anzeige. 